\title{
The Course in Geography in the State Normal School at Salem, Mass.
}

\section{William Charles Moore}

To cite this article: William Charles Moore (1904) The Course in Geography in the State Normal School at Salem, Mass., Journal of Geography, 3:4, 163-178, DOI: $10.1080 / 00221340408985495$

To link to this article: http://dx.doi.org/10.1080/00221340408985495

曲 Published online: 12 May 2008.

Submit your article to this journal $\widetilde{ }$

Џ Article views: 4

Q View related articles ¿ 


\title{
THE COURSE IN GEOGRAPHY IN THE STATE NORMAL SCHOOL AT SALEM, MASS.
}

\author{
BY WILIIAM CHARLES MOORE \\ Instructor in Geography, State Normal School, Salem, Massachusetts
}

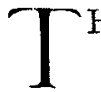

HE State Normal School at Salem, Massachusetts, is most favorably situated in a locality rich in geographical illustrations. Looking northward from the windows of the school building the principal industrial features of a moderate sized city, including a cotton mill, shoe factories, and a tannery, are easily identified. Towards the northeast is the harbor from which in times past the vessels of Salem sailed to all parts of the globe. (See Fig. 1.) Towards the west can be seen the line of railroad by which the city is connected with the chief center of trade in New England, and in this direction also is a large freight yard in which cars of all the principal railways of the Eastern United States are to be found. Looking in a southerly direction the eye is pleased and rested by fresh green meadows through which the tidal creeks reach out their glittering arms. Here also are fertile vegetable gardens, fields of waving corn, smoothly graded knolls, and, in the distance, numerous ranges of irregular rock hills spiked with dark green cedar trees. (See Fig. 2.) In one direction, therefore, are the agricultural and pastoral conditions typical of a rural comnunity, and in the other the important industrial and commercial features of city life.

The organization of the normal school provides a two years' course for the professional training of teachers, and a system of elementary schools which serve as the basis for the observation and practice-work of the normal school students. The work of the elementary department plans to prepare the children for admission to the high school in eight years.

The course of geography in the normal school proper consists largely in the observation and discussion of the methods of teaching pursued with elementary pupils. The outline of work actually performed by the classes of children is made the basis of these recitations and discussions. The instructor in charge of this department finds a very profitable part of his duty in supervising and teaching the lessons in geography in the elementary school. One marked result of this intimate and actual contact with the children is the unity which exists between the theoretical work of the normal school class room and what is actually accomplished with the elementary pupils. 
Perhaps another result is that some of the things which find an honored place in many of the geography outlines have been discarded in favor of a simpler, more rational, and less formal treatment. The study of geography in the elementary school is suffering from the severely logical method of teaching into which the work has been thrown by educators who have had little or no actual experience with children.

The regular work in geography with the children begins in our school with the third grade, that is, with the pupils who have attended school for three years, and continues through the eighth or last grade. During the first and second years of school life the nature study and language lessons have been creating a certain fund of experience which contributes more or less directly to the work in geography. During the third year this information is gathered together and additional experience created in the study of the surface features, occupations, people, map reading, simple weather phenomena, and productions.

This introductory treatment is of course very simple. It is intended as a preparation for the more careful study of these topics which comes in the next year. In that year, the fourth, the work with local surface features is followed closely by a study of distant areas which are similar in type to the local forms or which contribute more or less directly toward supplying the materials needed by the children for food, clothing, and shelter.

The study of the local surface features begun in the third year and continued throughout the fourth year is based upon the usefulness of the hills, valleys, and plains to the people of this community in affording suitable building sites, in determining the location of streets, roads, and railways, in furnishing a food supply, and in giving beauty and variety to the landscape.

The physiographical aspect of the hills, valleys, and plains, although not ignored, is not made the starting point. For example, within easy reach of the school building are various illustrations of rock hills and gravel hills. But the study of hills as individual things, separate from any obvious relation to the life of the community, is not of geographical importance. Instead, therefore, of selecting types from the unsettled district to the south and west where, although numerous hills of both kinds are to be found, few of them are conspicuous for their usefulness, we turn towards the settled area, for it is here that the surface features are in a more intimate relation to the daily life of the people.

The gravel hills within the settled portion of the town have streets laid out upon their surfaces, the approaches to their summits are in 


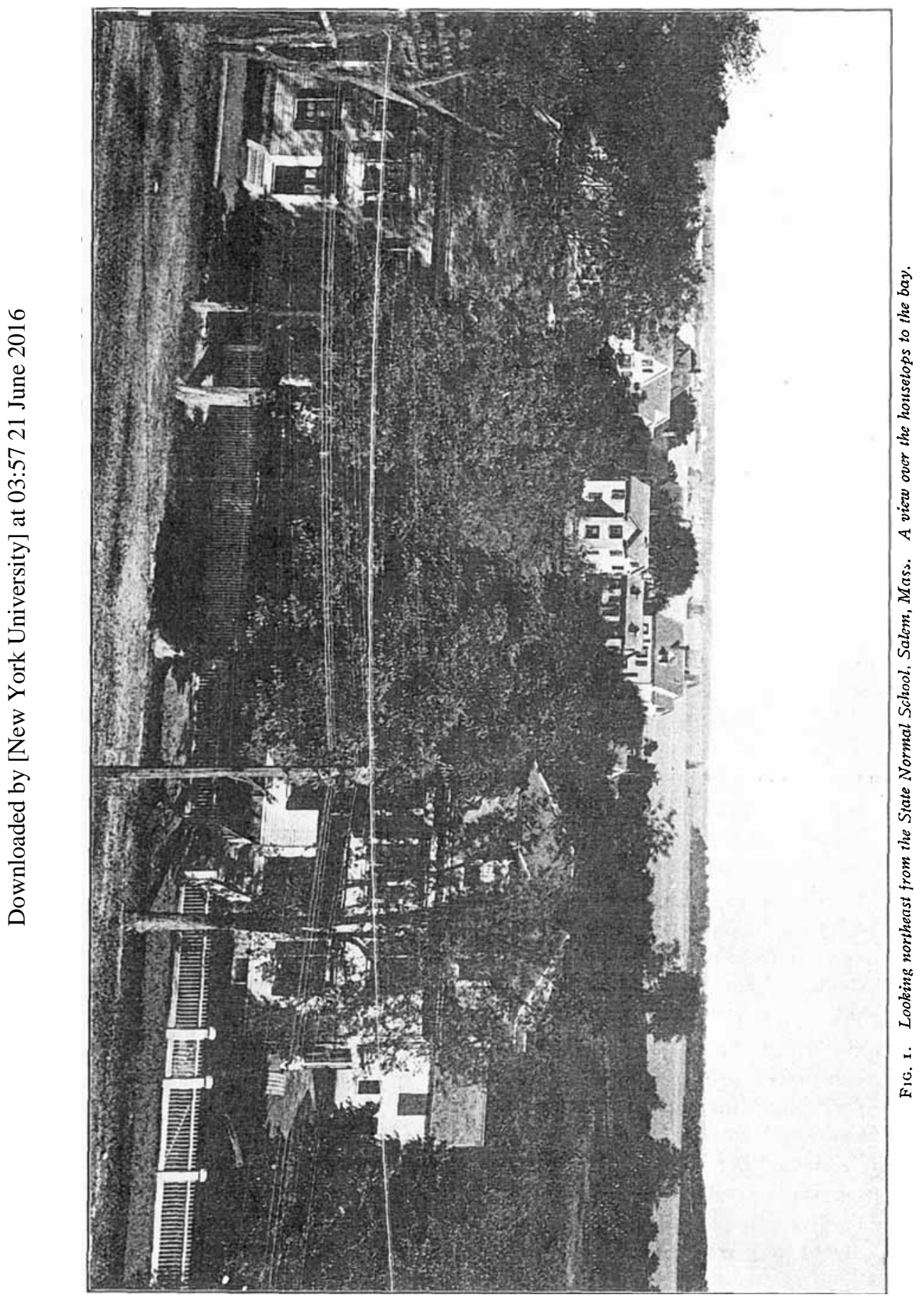


most cases easy, and the sides and tops of the hills are well built upon. The nearby rock hills, on the contrary, are not laid out in building lots, there are few houses upon them, and the area is used for little more than pasture land. Some of the hills, therefore, afford desirable building sites, and some do not. These facts are easily within the everyday experience of the pupils and may be considered also as coming within the range of their natural interests.

The explanation of these facts leads in a very simple way to a recognition of the difference in structure between rock hills and gravel hills. The pupil soon discovers that in every case the hills that are not occupied by buildings are of solid rock. The reason is that the blasting and excavating necessary for the construction of cellars adds considerably to the cost of building. Further, the laying out of streets upon the rock hills is almost prohibited by the steepness and irregularity of their slopes. The hills that are well built upon are found by the pupils to be composed of gravel and sand. This loose material offers little resistance to the pick and shovel. As a result streets are laid out without much difficulty and the erection of houses is encouraged.

The control which the surface features have exerted in determining ordinary lines of travel is well illustrated in the location of Lafayette Street, the main thoroughfare. Although in the beginning it was simply a rough country road from Salem to Marblehead, the fact nevertheless remains that throughout its entire length it avoids both the highest and lowest parts of the land. Thus the steep grades of the hills as well as the marshy lowlands, which at times must have been quite impassable, are both avoided. The influence of the topography upon the location of other streets is also easily seen.

To the south of the school building in the agricultural area before referred to there is good opportunity to study the usefulness of the surface features in providing a supply of food. Here upon the flat stretches and gentle slopes where the loam is fine and dark are the vegetable gardens; on the lowlands, where the soil is too wet for planting, the rich green grass gives promise of an abundant hay crop; and upon the southern slopes of the gravel hills are fields of waving corn. The rock hills with their steep sides and their gravelly soil offer little encouragement to cultivation and are therefore used only for grazing.

This brief description indicates the kind of work which receives emphasis in the study of local surface features. Whenever it is possible to do so without making the instruction stiff and formal the attention of the pupils is directed to the effect of the diversity of the surface 


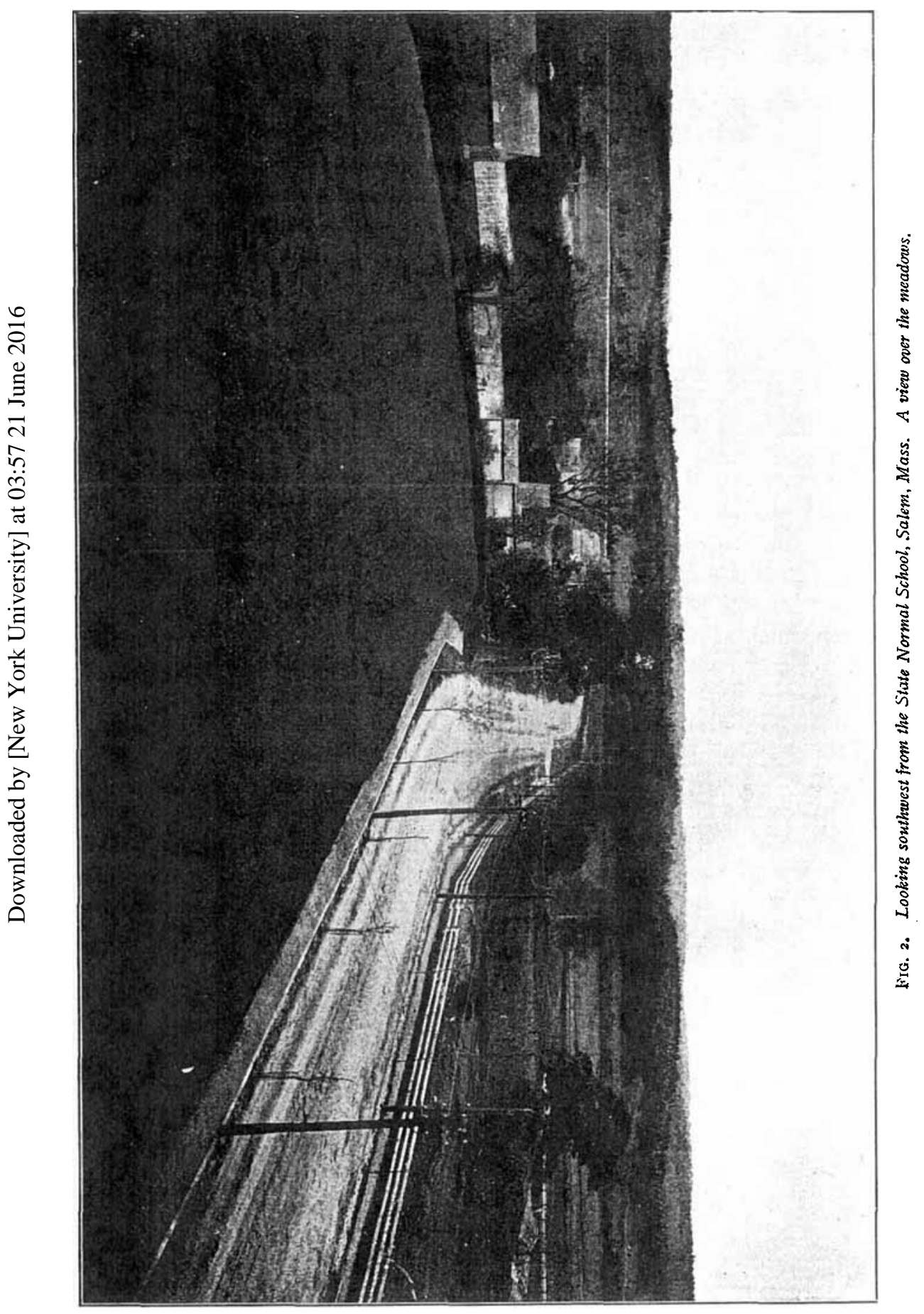


features in giving beauty and variety to the landscape. It is impossible to indicate, within the limits of this article, the numberless details in the study of the home geography which the very favorable situation of the school building makes not only possible but easy. Let me emphasize the fact that the study of the locality does not stop with simply observing and describing the characteristics of the hills, valleys, and plains, although this in itself would be a very commendable aim; it includes a recognition and emphasis of those relations of the local geographical features to the life of the people of this community which help to explain the control which distant geographical features exert upon the distribution of the world's population.

The knowledge of the position and characteristics of the natural and artificial surface features of the neighborhood gained in this study of the local geography is a very important basis for the first work in map reading. In developing this line of thought the children have the advantage of a very carefully constructed model of the locality surrounding the school building. This model is fashioned in putty. Its horizontal scale is thirty-four inches to the mile, and its vertical scale is one inch to forty-five feet. Upon it the hills, valleys, plains, coast line, harbor and mill pond, streets and railways are shown. It is not used, however until after some familiarity with the various natural and artificial surface features has been gained. Then the pupil is led to make a close association between the actual features of the locality and their representations upon the model, and the study of surface features goes hand in hand with the study of the local maps. The details of this work can not be included in this description.

We have found, by the way that the almost universal device recommended to teachers of having the pupils develop logically the map of the neighborhood step by step from the plan of the pupils' desks is not a good way to teach young children what drawing to a scale means. In the first place the careful work required for good results is not interesting to children of that age; in the next place, the results, even after considerable effort on the part of the teacher to give the work an acquired interest to the pupils, are slovenly and unsatisfactory. Finally, it can be said, the work is wholly unnecessary, for the pupils from the kindergarten upward, in their clay modeling and outline drawing, have been making use of the principles involved in representation to scale. All that is really necessary at this time is to show the children, by means of photographs of themselves, of the teacher, and of scenery with which they are familiar, the necessity for making the features that are 
smaller than the others in nature the smaller parts in the representation, and that each part in the picture or model is made the proper size to look right.

Following the work with the model of the neighborhood and closely associated with it and with the features out of doors comes a slope-line map of the same scale. The slope lines are lines which indicate the paths which running water would take in flowing down the hills. The work with this map, therefore, is very closely associated with the study of local drainage.

A contour map of the home locality with a vertical interval of seven feet comes next in the study of map reading, and prepares the way for a very intelligent appreciation of the Salem sheet published by the United States Geological Survey. It also leads directly to an interpretation of wall maps like the Sydow-Habenicht.

The work with the series of local maps is found to be an exceedingly important and valuable part of the course in geography. There are many interesting details connected with the development of this topic with the children which must be omitted from this article for want of space. "Without maps true geography teaching is impossible," but with maps like those used in this school the work takes on a concrete character which gives an interest and reality to the lessons that is most gratifying.

The study of distant surface features implies considerable progress in the reading of maps. The successful interpretation of the map symbols, however, will depend upon the thoroughness with which the study of the home locality has been pursued in connection with the local map. The use of pictures and the ability to form good mental images from verbal descriptions are also indispensable.

The plan by which the pupils in this school are led to an understanding of maps of distant places through a study of local maps has already been outlined in part. The steps have been so natural and easy that when the map of North America is reached the pupil recognizes at once the meaning of most of the conventional symbols. Just as soon as these have been named, suitable pictures of important features are shown. These pictures help the process of visualization by giving life and reality to the places represented upon the map. A picture of the Arctic coast line, one of the tropical shores of Central America, others of the coast lines of New England, New Jersey, Florida, California, and Alaska; views of the Rocky Mountains, the great plains, the prairies, the tundras, and of the Mississippi and other rivers- 
all of these are recognized, described, and associated with the particular area upon the map or with the appropriate symbol.

The study of the map (Sydow-Habenicht) illustrated by pictures and supplemented by verbal descriptions is made from this time on the basis of every geography lesson. Those distant surface features which are intimately connected with the lives of the people in this locality are studied first. The pupils recall the various needs in their own climate, and some of the more important commodities of life are traced back to their region of production. Then pictures which illustrate the conditions under which these things are grown or raised are used. The significant things in the picture-the character of surface, kind of soil, climatic conditions, productions; and people-are looked for and emphasized.

The wheat fields, grazing sections, garden farms, fruit districts, lumber regions, cotton and sugar plantations, and the mining and manufacturing centers of North America in particular and the world in general are recognized and studied as the work progresses. The control which relief, climate, and soils exert over natural productions is continually kept before the pupils, and frequent reference is made to the local conditions which illustrate these relations.

The study of these industrial regions leads almost immediately to the recognition of the physiographic types-prairies, coastal plains, flood plains, delta plains, tundras, mountainous regions and coastal forms, and the relation of the rivers to these surfaces features.

The topics, weather, climate, and natural productions receive due attention in the work of the third and fourth years. The aim in the study of the weather is to secure definiteness in the observation of characteristic phenomena, and to acquire the experience necessary for a rational understanding of climatic conditions. Instead of a formal record kept day after day the teacher is expected to take advantage of the opportunities as they occur for studying typical conditions.

The study of natural productions-plants, animals, and mineralsis closely related to the so-called nature work. The geographical aspect of the study of the organic side of nature consists largely in picturing and describing the plants and animals in their relation to the climatic conditions and physical features. This work, like the study of People, can be done most intelligently, not as a separate topic, but in connection with the work on relief, drainage, and coastal forms.

A summary of the work which is attempted in the fourth year, of which the above is only a partial and very brief description, is as follows: 
Relief, Drainage, and Coastal Forms.

Local surface features studied in detail.

School buildings, dwellings, factories, streets, in relation to general surface features.

Hills, valleys, plains, and coastal forms of the neighborhood.

Surface drainage in relation to hills, valleys, and plains.

Distant portions of landscape seen from schoolroom windows.

Usefulness and beauty of forms of land and water.

Distant surface features studied in their relation to life.

Plains: prairies, coastal plains, western plains, tundras, pampas, llanos, selvas, steppes, etc.

Mountains: Appalachian and Rocky Mountain highlands; Andes, Alps, Himalayas.

Rivers and valleys: Mississippi, St. Lawrence, Columbia, Mackenzie, Yukon, Colorado, Hudson, Ganges, Indus, Yang-tse, Nile, etc.

Coastal forms: irregular coast lines, harbors; regular shore lines. Rocky, sandy, and marshy coasts.

Map Reading.

Position: distance, cardinal directions.

Local maps: model, slope line and contour maps; Salem sheet.

Maps of distant places: wall maps, globes.

Natural Phenomena.

Forms of water: Atmosphere. Observations of sun, moon, stars. Climate.

Weather observations at characteristic times; distant climatic conditions.

Productions.

Minerals.

Plants and animals.

People.

Races: life and surroundings of people recognized in study of distant surface features.

Occupations: industrial conditions of home locality and distant places.

Commerce: inland and maritime trade of Salem.

The pupil at the end of the fourth year of school life has gained a fairly good knowledge of his own locality and considerable information concerning distant physical features, climate, and people.

During the next year, in the study of the earth as a whole, the aim is to give the world-wide views of these same geographical phenomena. 
The larger features of relief, drainage, and coast line, already described to some extent as individual things are now recognized as a part of and in relation to the whole earth.

The various things considered are form and size of the earth, earth in space, rotation, land and water divisions, latitude and longitude. The relief, drainage, coast lines, climate, and productions of the world and the topic People.

The spherical form of the earth is not a new idea to the pupils, and the purpose at this time is to furnish some reasons for the belief. The usual proofs are presented and illustrated by means of objects, pictures, and diagrams, but the teaching does not stop with the apparatus. By means of the imagination, with the device out of sight, the facts are applied to the earth itself.

To picture the earth in space is a difficult thing, even for adults, and it ought not to be attempted by children without previous observation of the moon. Some basis for imagining the earth in space may also be obtained by looking at pictures representing the earth seen along distance away, and if the mental image which the pupils acquire is nothing more than the memory of a good picture interpreted in terms of their observation upon the moon, the teaching need not be counted a failure.

The rotation of the earth is also something which requires a welltrained imagination to perceive. Usually the teaching of this topic amounts to nothing more than a mere juggling with objects. The geographical phases of rotation, however, include not much more than a study of day and night, and since the alternation of light and darkness is something within the experience of every child this is therefore made the starting point in teaching rotation.

The pupils describe the apparent movement of the sun from morning until evening. They think also of the possible path during our night. They are then told what people at one time believed and what the facts really are. Then comes the work with objects, not with a candle or lamp, but with a sphere held in the sunlight. This objective demonstration is followed by the application of these facts and relations to the earth itself. The details of these lessons have been carefully worked out, but space forbids more than this brief mention.

Small hand globes are supplied each pupil, and are constantly used in the naming and description of the divisions of the earth's surface into land and water, continents and oceans, and hemispheres. Pictures of mountains, plains, deserts, coast line, Arctic scenery, and tropical vegetation are associated with particular areas and appropriate symbols upon the globe. 
The primary highlands of the world, the lowlands and basins, the relation of drainage to highlands, lowlands, and basins are studied in the order named. New facts are not so much in evidence at this time, although of course no opportunity is lost to broaden and clarify the pupils' knowledge. The work has the character of a summary in which the aim is to see the world features in their relation to each other and to the whole.

The study of the climate of the world-heat belts, winds, and rainfall-is one of the most important and perhaps most difficult parts of the work of the fifth grade. The successful presentation of this topic requires very careful teaching. The writer was, moreover, inclined to believe at first that even under very favorable condutions the work might prove too difficult for the children, but actual experience has proved this not to be the case. Indeed, in the succeeding grades we find that the facts and their simple explanations which have been taught at this time constitute a very reliable part of the children's geographical information.

It is impossible to describe within the limits of this article the numerous concrete illustrations which are brought in to teach the fundamental facts about climate, nor to dwell upon the use which is made of pictures and stories in giving life and meaning to verbal statements. It must be remembered that the work here outlined depends very much for its success upon the previous preparation of the pupils, and upon the closeness and unity with which the work has been organized.

The line of thought is in general as follows: The location upon the globe of the warmest parts of the earth, the coldest parts, and the places of intermediate temperature. This is review. Then comes the explanation of these conditions by recalling the observations which the pupils have made upon the relation between the inclination of the sun's rays and the morning, evening, and noontime temperatures, and also the relation between the sun's meridian altitude and the seasonal variations in temperature. The importance of these observations in explaining fundamental differences in temperature upon the earth's surface is shown by means of a slated globe and a cardboard ring with parallel lines drawn upon it to represent the sun's rays.

The distribution of temperature upon the earth's surface as determined by latitude and as modified by the relation of land and water, is presented to the eye by means of a heat belt globe. Upon this globe the cold polar caps are shown in dark blue, the cool belts in light blue, the warm belts in green, and the hot belt in orange. This heat belt 
globe is referred to constantly in the subsequent study of continents and countries.

The study of winds and rainfall of the world is closely connected with the work on heat belts and is based upon previous observation and experimental work. Ocean currents are taught as an application of the effect of the planetary circulation of the atmosphere upon the ocean waters.

The topic, World Productions, offers an excellent opportunity for summarizing and relating a large part of the geographical information already acquired and for emphasizing the control which the surface features, temperature and moisture, exert upon the distribution of plants and animals. Further, a discussion of the importance of the products of the world in supplying man's needs, of the land and water routes by which the surplus productions are sent to different parts of the world, and of the location of the principal trade and transportation centers, is valuable in showing the relation of the earth to man.

The study of People is pursued in connection with every topic. in geography. As a result the pupils acquire in the most natural and informal way considerable information concerning the habits, customs, and the degree of civilization of the different races. The aim at this time, towards the close of the fifth year of school life, is to recognize in a somewhat more logical way than before the distinctive characteristics of each race, and to note their original and present distribution upon the earth's surface. This work give; a good opportunity for recognizing the different states of society and for discussing, in a simple way, the progress of the human race from savagery through a condition of barbarism to civilization.

The work of the sixth and seventh grades is concerned with a study of each continent as a unit. The particular aims are to recognize the most important physiographic regions in each grand division, to describe the climate, and to trace the influence of relief, drainage, climate, and soils in determining the development of industrial and commercial conditions. The division of each continent among the nations of the earth, and the characteristic features of their different political institutions and habits of life, is now an important part of the work. The relation of distant people to ourselves in particular and to the rest of the world in general is, of course, kept constantly in mind. 
The outline of the work of the sixth and seventh grades is given below: The Continents.

North America.

Position.

Hemispheres, relation to oceans and other continents, latitude and longitude.

General Description.

Outline.

Relief: highlands, lowlands.

Drainage: Atlantic, Pacifie, Arctic, interior.

Coast line: regularities, irregularities, harbors.

Climate: heat belts, winds, rainfall.

Productions.

People.

Physiographic Regions.

Atlantic Coastal Plain.

Position in North America; direction and distance from home; relation to us in supplying needs.

Surface features; slope, soil, drainage; fall line; geographic history.

Climatic conditions; effect of proximity of ocean.

Productions in relation to surface features and climate.

Location of cities as centers of accumulation and distribution.

Routes of transportation-by rail, by water.

Gulf Coastal Plain.

Location.

Description; surface features, history, climate, agricultural products.

Leading cities and trade routes.

Northern Plain.

Location in North America; direction and distance from home; means of getting there.

Description; surface features, history, climate; comparison with Gulf plain.

Productions and occupations.

Prairies.

Location, extent, direction, and distance from home; relation to us in supplying needs.

Description: surface features, history; climate, agricultural products. 


\begin{tabular}{lll}
\hline 176 & THE JOURNAL OF GEOGRAPHY & Apri1 \\
\hline
\end{tabular}

Commercial routes: Great Lakes, rivers, railroads.

Leading cities.

Great Plains.

Location, extent, relation to prairies.

Description; surface features, climate, industries.

Cities.

Rocky Mountain Highland.

Extent, general direction, principal ranges, and subdivisions.

Description and comparison of physical features, climate, drainage, and industries of Rocky Mountains, the Pacific ranges, Great Basin, Colorado and Columbia plateaus, Yukon region, and the highland of Mexico and Central America.

Appalachian Highland.

Extent, general direction, principal divisions.

Comparison with Rocky Mountain highland.

Description of physical features, climate, and drainage of the mountainous region and the Piedmont belt.

St. Lawrence Basin.

Countries.

Location, extent, comparison of relief, climate, soils.

United States.

Groups of States.

Description of each section.

Cities.

Canada and Newfoundland.

Political organization.

Industrial conditions.

Mexico, Central America, and West Indies.

South America.

Position (same as for North America).

General Description (same as for North America).

Physiographic regions.

Description of surface features and climate of Andes, Brazilian and Guiana highlands, the selvas, pampas, and llanos, the desert of Atacama, and the plain of Chile.

Plants, animals, and people in relation to surface features and climate.

Countries.

Location, extent, political organization.

Brazil.

Relation to physiographic features and climate. 
Industrial conditions.

Cities and trade routes.

Similar plan for the other countries.

Observation Work (Carried on parallel with the study of The Continents)

Meteorological.

Prevailing winds of summer and winter.

Changes in weather caused by passage of storms.

Weather map.

Astronomical.

Sun; time and place of rising and setting, meridian altitude. Moon; position and shape of young moon and changes throughout the month.

Planets; evening and morning stars, names of planets.

Stars; circumpolar constellations, other groups.

Local Geographical Features.

Weathering, formation of soils. Gutter streams.

Industrial conditions.

Continents (Continued).

Eurasia.

Position, Relative Size, Outline.

General Description (see North America).

Physiographic Regions.

Eurasian highland; principal mountain ranges, plateaus of Mongolia, Tibet, Iran, Asia Minor.

Northern lowland; tundras, forest plains, steppes.

Plains of Manchuria; China, Indo-China, India, and Mesopotamia.

Plateaus of Arabia and the Dekkan.

Plateaus and plains of Europe.

Countries of Eurasia.

Location, extent, political organization.

Industrial conditions.

Cities and trade routes.

Africa.

Position, size, shape, coast line.

Relief, climate, drainage.

Productions, people countries.

Australia and the Island Groups.

Position, size, coast line.

Relief, climate, drainage.

Productions, people, government. 
The work of the eighth year consists principally in a study of the life of the world in its geographical relations. The discussions depend to a great degree upon current events and cover matters of local interest and happepings of national and foreign importance. The work includes the recognition of the geographical significance of the particular event, a discussion of the conditions leading up to it or surrounding it, and a study of the people-their characteristics, government, territory, and international relations.

In addition to the study of the life of the world the work of the eighth year includes something of astronomical geography and physical geography.

The study of the earth in its astronomical relations consists in a review of the form, size, and rotation of the earth, latitude and longitude, and the presentation of the topic, Light Zones, with a discussion of the causes of change of seasons and variation in the length of day and night.

The topics in physical geography include a study of glacial phenomena, wave and river action, and soils. The character of the teaching throughout the previous grades has been such that the pupils have already gained considerable information about these phenomena and the aim at this time is to summarize and group the facts.

The outline of the eighth year's work is as follows:

Life of the World in its Geographical Relations.

Current geographical events.

Local, New England, national, foreign.

Geographical conditions affecting the event.

People concerned; characteristics, government, territory, -international relations; nations.

Man; races, distribution, advancement, government, religion.

Industries of the world; importance, development; commercial relations, trade routes.

Leading nations; relative importance, territorial possessions, characteristics of people, political institutions, industrial conditions, commercial relations.

Astronomical Geography.

Form, size, rotation of the earth; latitude and longitude.

Revolution of the earth, light zones, change of seasons, length of day and night.

Physical Geography.

Glacial phenomena; river and wave action; soils. 